Research Article

\title{
Contribution of DNA repair xeroderma pigmentosum group D genotypes to pancreatic cancer risk in the Chinese Han population
}

\author{
Dong Yan ${ }^{1}$, Xiao-Hui Liang ${ }^{2}$, Wei Ding ${ }^{1}$, Xin-Jian $\mathrm{Xu}^{3}$ and Xi-Yan Wang ${ }^{4}$ \\ ${ }^{1}$ Department of Hepatopancreatobiliary Surgery, Affiliated Tumor Hospital of Xinjiang Medical University, \\ Urumqi, Xinjiang, China. \\ ${ }^{2}$ Department of Hypertension, First Affiliated Hospital of Xinjiang Medical University, Urumqi, Xinjiang, \\ China. \\ ${ }^{3}$ Department of Pancreatic Surgery, First Affiliated Hospital of Xinjiang Medical University, Urumqi, \\ Xinjiang, China. \\ ${ }^{4}$ Department of Xinjiang Research Institute of Cancer Prevention and Control, Affiliated Tumor Hospital of \\ Xinjiang Medical University, Urumqi, Xinjiang, China.
}

\begin{abstract}
This study aimed to determine the association between the polymorphisms and haplotypes in the xeroderma pigmentosum group D (XPD) gene and the risk of pancreatic cancer in the Chinese Han population. SNaPshot was used for genotyping six SNP sites of the XPD gene. Comparisons of the correlations between different genotypes in combination with smoking and the susceptibility to pancreatic cancer were performed. Individual pancreatic cancer risk in patients who carry mutant $C$ alleles $(A C, C C$, and $A C+C C)$ at rs13181 increased $(p<0.05)$. Taking non-smoking individuals who carry the AA genotype as a reference, and non-smoking individuals who carry mutant allele $C(A C+C C)$, the risk of pancreatic cancer increased by 3.343 times in individuals who smoked $\geq 20$ cigarettes daily, 3.309 times in individuals who smoked $\geq 14$ packs per year, 5.011 times in individuals who smoked $\geq 24$ packs per year, and 4.013 times in the individuals who smoked $\geq 37$ packs per year $(P<0.05)$. In addition, haplotype analysis revealed that haplotype AGG, which comprised rs13181, rs3916874 and rs238415, was associated with a 1.401 -fold increase in pancreatic cancer risk $(p<0.05)$. We conclude that the polymorphism of XPD Lys751Gln ( $r$ 13181) in combination with smoking contributes to increased risk of pancreatic cancer in the Chinese Han population. Haplotype AGG might be a susceptibility haplotype for pancreatic cancer.
\end{abstract}

Keywords: Pancreatic neoplasm, human xeroderma pigmentosum group D, polymorphism, smoking.

Received: February 20, 2017; Accepted: June 12, 2017.

\section{Introduction}

Pancreatic cancer (PC) is highly malignant, has an insidious onset, and lacks early diagnostic methods. Furthermore, more than $80 \%$ of patients have lost their chance of surgery when they first visit a doctor, and overall five-year survival rate is approximately 5\% (Siegel et al., 2013). To date, the exact mechanism of PC remains unknown. Smoking, type 2 diabetes mellitus (T2DM), body mass index, alcohol consumption, and family history are the most consistent epidemiological risk factors for PC (Larsson et al., 2007; Maisonneuve and Lowenfels,2010; Jacobs et al., 2010). Multiple cohort and case-control studies have con-

Send correspondence to Xi-Yan Wang. Department of Xinjiang Research Institute of Cancer Prevention and Control, Affiliated Tumor Hospital of Xinjiang Medical University, No. 789 of Suzhou East Street, New Urban District, Urumqi 830011, Xinjiang, China. E-mail: wangxy25641@sina.com sistently demonstrated an association between PC and cigarette smoking, particularly among heavy smokers (Iodice $e t$ al., 2008; Bosetti et al., 2012).

A study reported that carcinogens from cigarettes may reach the pancreas via blood, or may return via bile, so contents of DNA-carcinogen adducts in smokers are higher than in non-smokers (Talamini et al., 2010). The human xeroderma pigmentosum group D (XPD) gene can repair damage induced by bulky DNA adducts and maintain genomic stability. XPD are the major components of nucleotide excision repair (NER) pathway and transcription factor IIH (TFIIH), which are involved in gene transcription and NER by unwinding DNA around the lesion (Benhamou and Sarasin, 2005). It has been reported that mutations of the XPD gene diminish its helicase activity, resulting in defective NER capacity for bulky DNA adducts and transcriptional activity, and in an abnormal response to apoptosis (Taylor et al., 1997). Mutations and defects in XPD gene 
may be closely related to tumorigenesis. The most widely investigated XPD polymorphism in association with cancer susceptibility comprise a non-synonymous A to C substitution in exon 23 causing a lysine (Lys) to glutamine (Gln) substitution in codon 751 (Lys751Gln, rs13181) (Shen et al., 1998; Benhamou and Sarasin, 2002). Some studies have reported significant associations between codon 751 variants and predisposition to many types of cancer, including melanoma (Kertat et al., 2008), lung (Wu and Ding, 2014), head and neck (Yuan et al., 2011), bladder (Xiong et al., 2014), and breast (Yan et al., 2014). The variant genotypes are both associated with lower DNA repair capacity and a higher level of DNA adducts left in the genome (Shen et al., 1998; Lunn et al., 2000; Benhamou and Sarasin, 2002). A few studies investigated the association of XPD genotype with PC risk (Jiao et al., 2007; McWilliams et al., 2008). However, the results of these reports remain inconclusive and none investigated the Chinese Han population, which is genetically conservative and different from Western populations.

Tagging SNP (tag-SNP) can improve validity of analyzing the correlation between candidate genes and disease. In the current study, to better understand the pivotal roles of XPD, we adopted tag-SNP with SNP to enroll functional site - codon 751. Because of the known ethnic variation in PC risk and genotype distribution, the current study focused on the Chinese Han population only, and analyzed the contribution of XPD genotypes to PC susceptibility and their interactions with smoking and other clinical factors.

\section{Materials and Methods}

\section{Study subjects}

A total of 226 patients with pancreatic cancer, who were admitted in the Affiliated Tumor Hospital of Xinjiang Medical University and the First Affiliated Hospital of Xinjiang Medical University from December 2007 to August 2015, were enrolled in this study. Among these patients, 140 underwent pancreaticoduodenectomy, 23 underwent ${ }^{125} \mathrm{I}$ implantation and palliative surgery (biopsy was performed during surgery), 59 underwent pancreatic body and tail (combined with spleen) resection, and four underwent CT-guided fine needle puncture biopsy. All patients were confirmed as having PC by histopathological examination. Two hundred and sixty-three subjects, who were admitted in the First Affiliated Hospital of Xinjiang Medical University during the same period and had no previous history of pancreatic disease were assigned as controls after initial random sampling. The exclusion criteria of the case and control groups included previous malignancy, metastasized cancer from other or unknown origin, and incomplete general information.

All enrolled participants were volunteers from the Chinese Han population. They completed a questionnaire and provided peripheral blood samples. Demographic in- formation including age, gender, smoking and drinking status and other factors were obtained through a structured questionnaire interview. Subjects with continuous or cumulative smoking history for six months or more were defined as smokers, and the cumulative amount of smoking was calculated as packs/year $=$ daily smoking amounts $/ 20 \mathrm{x}$ years of smoking. Drinking was defined as having at least one drink every week for more than six months (Qian et al., 2014). Body mass index (BMI) was calculated from height and weight using the BMI formula (BMI=weight in kilogram divided by the square of height in meters). Diabetes and family medical history were obtained by self-report using a questionnaire at the time of enrollment. All patients signed an informed consent. The study protocol was approved by the Ethical Committee of the First Affiliated Hospital of Xinjiang Medical University.

\section{Blood collection and DNA extraction}

Three milliliters of peripheral blood collected from each participant was placed in EDTA tubes, and stored in a freezer at $-80^{\circ} \mathrm{C}$ within $30 \mathrm{~min}$ after it was collected. The genomic DNAs were extracted from blood samples using a DNA blood kit (BioTeke, Beijing, China), according to manufacturer's instructions.

\section{SNP selection and genotyping}

According to the Hapmap database (http://hapmap.ncbi.nlm.nih.gov/), data were analyzed using HaploView 4.0 software, minor allele frequency was adjusted to 0.15 , the lower limit of linkage disequilibrium (D') was greater than 0.8 , and an $\mathrm{r}^{2}$ of 0.8 was selected as the threshold for the analyses. As a result, 5 tag-SNPs (rs3916874, rs238415, rs50872, rs50871 and rs238406) were selected from the HapMap covering the XPD gene. XPD codon 751 (rs13181), which is the most studied in the literature, was the functional site that encoded nonsynonymous amino acid changes, and was enrolled into this study as well.

PCR primers and extended primers (Table 1) were designed using the Primer5 software. PCR assays were set up as follows: $1 \mu \mathrm{L}$ of $10 \mathrm{x}$ hot start Taq buffer, $1.2 \mu \mathrm{L}$ of $\mathrm{MgCl}_{2}, 1.5 \mu \mathrm{L}$ of deoxy-ribonucleoside triphosphate (dNTP) mixture, $0.2 \mu \mathrm{L}$ of hot start Taq DNA polymerase (Qiagen,GER), $1 \mu \mathrm{L}$ of sample DNA, $1 \mu \mathrm{L}$ of multiple PCR primers, and ultra pure water was added to produce $10 \mu \mathrm{L}$. Reaction conditions were as follows: pre-denaturation at 95 ${ }^{\circ} \mathrm{C}$ for $2 \mathrm{~min}, 11$ cycles of $94{ }^{\circ} \mathrm{C}$ for $20 \mathrm{~s}, 65^{\circ} \mathrm{C}$ for $40 \mathrm{~s}$ and $72{ }^{\circ} \mathrm{C}$ for $90 \mathrm{~s}$, followed by an extension step at $72{ }^{\circ} \mathrm{C}$ for 2 min and cooling to $4^{\circ} \mathrm{C}$. PCR products were purified using an Exo/SAP protocol (Applied Biosystems, Foster City, CA, USA) according to the manufaccturers instructions. The PCR products were labeled by the alkaline phosphatase-labeled streptavidin biotin/exonuclease I (ExoI) method, using $1 \mathrm{U}$ of shrimp alkaline phosphatase (SAP; Promega, Madison, WI, USA) and 1 U of ExoI (New Eng- 
land Biolabs, Beverly, MA, USA). The labeling reaction was performed at $37^{\circ} \mathrm{C}$ for $1 \mathrm{~h}$, followed by inactivation at $75^{\circ} \mathrm{C}$ for $15 \mathrm{~min}$. The $\mathrm{SNaPshot}$ extension reaction system consisted of $5 \mu \mathrm{L}$ of the SNaPshot multiple reaction kit agents (Applied Biosystems), $2 \mu \mathrm{L}$ of purified multiple PCR products, and $1 \mu \mathrm{L}$ of the extension primer mixture, and completing the volume to $10 \mu \mathrm{L}$ with ultra pure water. The PCR cycling conditions of the primer extension reaction were as follows: pre-denaturation at $96{ }^{\circ} \mathrm{C}$ for $1 \mathrm{~min}$, followed by 28 cycles of $96^{\circ} \mathrm{C}$ for $10 \mathrm{~s}, 50^{\circ} \mathrm{C}$ for $5 \mathrm{~s}$ and 60 ${ }^{\circ} \mathrm{C}$ for $30 \mathrm{~s}$, followed by an extension step at $60{ }^{\circ} \mathrm{C}$ for 1 min, and cooling to $4^{\circ} \mathrm{C}$. Next, $1 \mathrm{U}$ of SAP was added to the $10 \mu \mathrm{L}$ extension product and the mixture was incubated at $37^{\circ} \mathrm{C}$ for $1 \mathrm{~h}$ then inactivated at $75^{\circ} \mathrm{C}$ for $15 \mathrm{~min}$. For data analysis, $0.5 \mu \mathrm{L}$ of the purified extension product were mixed with $0.5 \mu \mathrm{L}$ of fluorescent internal standard and $9 \mu \mathrm{L}$ of formamide reagent, and denatured at $95^{\circ} \mathrm{C}$ for $5 \mathrm{~min}$. The products were sequenced using an ABI 3130XL automatic DNA sequencer (Applied Biosystems) and analyzed using the GeneMapper 4 software.

\section{Statistical analysis}

SPSS 19.0 statistical software was used for statistical analysis. The Hardy-Weinberg equilibrium was tested for all SNPs in the control group. Chi-squared tests were used to assess differences in the distribution of genotypes and the SNP alleles between the case and control groups. Odds ratios (ORs) and 95\% confidence intervals (CIs) were calculated using multivariate unconditional logistic regression with adjustments for age and gender. Haploview software version 4.0 was used to generate linkage disequilibrium (LD) plots and assess the association between haplotypes and PC. A $p$-value $<0.05$ was considered to be statistically significant.

\section{Results}

\section{General characteristics}

Demographic characteristics and related risk factors of the subjects are shown in Table 2. The $X^{2}$-test showed that differences in age, gender, alcohol, and BMI between the case group and control group were not statistically significant $(p>0.05)$; there was also no significant difference with respect to diabetes history and family history of cancer $(p>0.05)$. Therefore, the effects of confounding factors on the results were avoided.

\section{The correlation of smoking and PC}

The risk of PC did not increase in smokers compared with non-smokers $(\mathrm{OR}=1.384,95 \% \quad \mathrm{CI}=0.896-2.259$, $p=0.150$ ), but the risk of PC increased in patients whose daily smoking amount was more than 20 cigarettes $(\mathrm{OR}=1.569,95 \% \mathrm{CI}=1.005-2.448, p=0.047)$. According to the cumulative smoking amount, the risk of PC was in- 
Table 2 - Comparison of clinical characteristics in pancreatic cancer patients and controls.

\begin{tabular}{|c|c|c|c|c|}
\hline $\begin{array}{l}\text { Clinical characteristics } \\
\text { (cases) }\end{array}$ & $\begin{array}{l}\text { Patients } \\
\text { group } 226\end{array}$ & $\begin{array}{l}\text { Control } \\
\text { group } 263\end{array}$ & $\begin{array}{c}\chi^{2} \\
\text { value }\end{array}$ & $p$ \\
\hline Age (years old) & & & 0.146 & 0.986 \\
\hline$\leq 49$ & 32 & 39 & & \\
\hline $50 \sim 59$ & 40 & 49 & & \\
\hline $60 \sim 69$ & 76 & 87 & & \\
\hline$\geq 70$ & 78 & 88 & & \\
\hline Sex & & & 1.335 & 0.248 \\
\hline Male & 138 & 147 & & \\
\hline Female & 88 & 116 & & \\
\hline Alcohol consumption & & & 3.120 & 0.077 \\
\hline Yes & 94 & 89 & & \\
\hline No & 132 & 174 & & \\
\hline Diabetes history & & & 1.672 & 0.196 \\
\hline Yes & 51 & 47 & & \\
\hline No & 175 & 216 & & \\
\hline $\mathrm{BMI}\left(\mathrm{kg} / \mathrm{m}^{2}\right)$ & & & 3.198 & 0.362 \\
\hline$<18.5$ & 64 & 59 & & \\
\hline $18.5 \sim 23.9$ & 83 & 97 & & \\
\hline $24 \sim 27.9$ & 47 & 69 & & \\
\hline$\geq 28$ & 32 & 38 & & \\
\hline Family history of cancer & & & 1.732 & 0.188 \\
\hline Yes & 31 & 26 & & \\
\hline No & 195 & 237 & & \\
\hline
\end{tabular}

$\mathrm{BMI}=$ body mass index

P-values were calculated from two-sided Chi-squared tests. creased by $0.767 \quad(\mathrm{OR}=1.767,95 \% \quad \mathrm{CI}=1.020-3.063$, $p=0.041)$ in patients who smoked $\geq 14$ packs per year, by $0.856(\mathrm{OR}=1.856,95 \% \mathrm{CI}=1.000-3.445, p=0.048)$ in patients who smoked $\geq 24$ packs per year, and by 1.209 $(\mathrm{OR}=2.209,95 \% \mathrm{CI}=1.041-4.686 . p=0.035)$ in patients who smoked $\geq 37$ packs per year (Table 3 ).

\section{Correlation analysis of PC susceptibility}

The genotype distributions of six SNP loci in the case and control groups were all in accordance with the HardyWeinberg equilibrium ( $p>0.05$, Table 4$)$. The $\mathrm{C}$ allele frequency of the rs13181 site in patients with PC in the case group was higher than in the control group $(p=0.005)$. Compared with individuals carrying the AA genotype, the risk of $\mathrm{PC}$ increased in patients carrying the mutant $\mathrm{C}$ allele (AC, $\mathrm{CC}$, and $\mathrm{AC}+\mathrm{CC}$ ) was $p=0.044, p=0.040$, and $p=0.012$, respectively. There was no significant difference in the genotype and allele frequency distributions of the five selected tag-SNP loci between the case group and control group ( $p<0.05$; Tables 4 and 5).

A haplotype analysis was performed to evaluate the frequencies of haplotypes based on the three polymorphisms within block 1 of XPD. Block 1 includes the completely linked rs13181, rs3916874 and rs238415 (Figure 1). The haplotype AGG was significantly associated with increased risk of $\mathrm{PC}(\mathrm{OR}=1.401,95 \% \mathrm{CI}=1.065-1.844$, $p=0.016$; Table 6).

Table 3 - Relationship between smoking and pancreatic cancer.

\begin{tabular}{|c|c|c|c|c|c|c|c|}
\hline \multirow[t]{2}{*}{ Smoking } & \multirow[t]{2}{*}{ Patients group (cases) } & \multirow[t]{2}{*}{ Control group (cases) } & \multirow[t]{2}{*}{ OR } & \multicolumn{2}{|c|}{$95 \% \mathrm{CI}$} & \multirow[t]{2}{*}{$\chi^{2}$} & \multirow[t]{2}{*}{$\mathrm{p}$} \\
\hline & & & & Lower limit & Upper limit & & \\
\hline \multicolumn{8}{|l|}{ Smoking } \\
\hline No & 126 & 167 & 1.00 & & & & \\
\hline Yes & 100 & 96 & 1.381 & 0.960 & 1.985 & 3.037 & 0.081 \\
\hline \multicolumn{8}{|c|}{ Amount of cigarettes a day } \\
\hline 0 (no smoking) & 126 & 167 & 1.00 & & & & \\
\hline$\leq 9$ & 15 & 16 & 1.243 & 0.592 & 2.608 & 0.331 & 0.565 \\
\hline $10 \sim 19$ & 27 & 31 & 1.154 & 0.656 & 2.032 & 0.248 & 0.619 \\
\hline$\geq 20$ & 58 & 49 & 1.569 & 1.005 & 2.448 & 3.960 & 0.047 \\
\hline \multicolumn{8}{|c|}{ Total (packs per year) } \\
\hline 0 (no smoking) & 126 & 167 & 1.00 & & & & \\
\hline$<14$ & 16 & 37 & 0.573 & 0.305 & 1.077 & 3.046 & 0.081 \\
\hline $14 \sim 23.9$ & 36 & 27 & 1.767 & 1.020 & 3.063 & 4.180 & 0.041 \\
\hline $24 \sim 36.9$ & 28 & 20 & 1.856 & 1.000 & 3.445 & 3.914 & 0.048 \\
\hline$\geq 37$ & 20 & 12 & 2.209 & 1.041 & 4.686 & 4.432 & 0.035 \\
\hline
\end{tabular}

$\mathrm{CI}=$ confidence interval; $\mathrm{OR}=$ odds ratio;

$P$ values were calculated from two-sided chi-squared tests. 
Table 4 - Characteristics of the 6 SNPs in XPD Gene.

\begin{tabular}{|c|c|c|c|c|c|c|c|c|}
\hline \multirow[t]{2}{*}{ SNP ID } & \multirow[t]{2}{*}{ Chromosome position } & \multirow[t]{2}{*}{ location } & \multirow[t]{2}{*}{ Base change } & \multicolumn{2}{|c|}{ MAF } & \multicolumn{2}{|c|}{ HWE $p$} & \multirow[t]{2}{*}{$p$} \\
\hline & & & & case & control & case & control & \\
\hline rs13181 & 45854919 & Extron23 & $\mathrm{A} / \mathrm{C}$ & 0.32301 & 0.24144 & 0.521 & 0.745 & 0.005 \\
\hline rs3916874 & 45856926 & Intron 17 & $\mathrm{G} / \mathrm{C}$ & 0.13496 & 0.16160 & 0.662 & 0.355 & 0.244 \\
\hline rs238415 & 45857235 & Intron 17 & $\mathrm{C} / \mathrm{G}$ & 0.35840 & 0.34791 & 0.189 & 0.113 & 0.732 \\
\hline rs50872 & 45862449 & Intron 12 & $\mathrm{C} / \mathrm{T}$ & 0.15708 & 0.19962 & 0.999 & 0.607 & 0.084 \\
\hline rs50871 & 45862515 & Intron 12 & $\mathrm{~T} / \mathrm{G}$ & 0.29203 & 0.29658 & 0.974 & 0.588 & 0.877 \\
\hline rs238406 & 45868309 & Extron6 & $\mathrm{C} / \mathrm{A}$ & 0.32079 & 0.32889 & 0.162 & 0.251 & 0.787 \\
\hline
\end{tabular}

$\mathrm{MAF}=$ Minor Allele Frequency, HWE $=$ Hardy-Weinberg Equilibrium.

$P$ values were calculated from two-sided chi-squared tests.

Table 5 - Association between polymorphisms of XPD gene in pancreatic cancer patients from the Chinese Han population.

\begin{tabular}{|c|c|c|c|c|c|c|c|}
\hline SNP & Genotype & Case & Control & OR $(95 \% \mathrm{CI})$ & $p$ & $\mathrm{OR}(95 \% \mathrm{CI}) \dagger$ & $p \dagger$ \\
\hline \multirow[t]{4}{*}{ rs13181 } & AA & 118 & 167 & $1.00($ reference $)$ & & & \\
\hline & $\mathrm{AC}$ & 70 & 65 & $1.524(1.010 \sim 2.301)$ & 0.044 & $1.535(1.015-2.320)$ & 0.042 \\
\hline & $\mathrm{CC}$ & 38 & 31 & $1.735(1.021 \sim 2.946)$ & 0.040 & $1.707(1.003-2.903)$ & 0.049 \\
\hline & $\mathrm{AC}+\mathrm{CC}$ & 108 & 96 & $1.592(1.108 \sim 2.287)$ & 0.012 & $1.596(1.109-2.298)$ & 0.012 \\
\hline \multirow[t]{4}{*}{ rs3916874 } & GG & 167 & 181 & $1.00($ reference $)$ & & & \\
\hline & $\mathrm{GC}$ & 57 & 79 & $0.782(0.524-1.167)$ & 0.228 & $0.778(0.520-1.165)$ & 0.223 \\
\hline & $\mathrm{CC}$ & 2 & 3 & $0.723(0.119-4.378)$ & 0.723 & $0.782(0.127-4.826)$ & 0.791 \\
\hline & $\mathrm{GC}+\mathrm{CC}$ & 59 & 82 & $0.780(0.525-1.158)$ & 0.217 & $0.781(0.524-1.163)$ & 0.223 \\
\hline \multirow[t]{4}{*}{ rs238415 } & $\mathrm{CC}$ & 102 & 123 & 1.00 (reference) & & & \\
\hline & $\mathrm{CG}$ & 86 & 97 & $1.069(0.723-1.581)$ & 0.738 & $1.504(1.017-2.224)$ & 0.056 \\
\hline & GG & 38 & 43 & $1.066(0.640-1.773)$ & 0.807 & $1.303(0.772-2.198)$ & 0.322 \\
\hline & $\mathrm{CG}+\mathrm{GG}$ & 124 & 140 & $1.068(0.748-1.526)$ & 0.718 & $1.444(1.004-2.076)$ & 0.051 \\
\hline \multirow[t]{4}{*}{ rs50872 } & $\mathrm{CC}$ & 161 & 172 & 1.00 (reference) & & & \\
\hline & $\mathrm{CT}$ & 59 & 77 & $0.819(0.548-1.223)$ & 0.328 & $0.823(0.550-1.232)$ & 0.344 \\
\hline & $\mathrm{TT}$ & 6 & 14 & $0.458(0.172-1.220)$ & 0.110 & $0.677(0.414-1.105)$ & 0.118 \\
\hline & $\mathrm{CT}+\mathrm{TT}$ & 65 & 91 & $0.763(0.520-1.120)$ & 0.167 & $0.766(0.521-1.126)$ & 0.175 \\
\hline \multirow[t]{4}{*}{ rs50871 } & $\mathrm{TT}$ & 112 & 135 & $1.00($ reference $)$ & & & \\
\hline & TG & 96 & 100 & $1.157(0.795-1.685)$ & 0.446 & $1.139(0.781-1.661)$ & 0.500 \\
\hline & GG & 18 & 28 & $0.775(0.407-1.474)$ & 0.436 & $0.904(0.653-1.251)$ & 0.542 \\
\hline & $\mathrm{TG}+\mathrm{GG}$ & 114 & 128 & $1.074(0.752-1.532)$ & 0.696 & $1.065(0.745-1.522)$ & 0.731 \\
\hline \multirow[t]{4}{*}{ rs238406 } & $\mathrm{CC}$ & 113 & 128 & 1.00 (reference) & & & \\
\hline & $\mathrm{CA}$ & 81 & 97 & $0.946(0.641-1.395)$ & 0.779 & $0.934(0.630-1.384)$ & 0.733 \\
\hline & AA & 32 & 38 & $0.954(0.559-1.627)$ & 0.812 & $0.979(0.568-1.689)$ & 0.940 \\
\hline & $\mathrm{CA}+\mathrm{AA}$ & 113 & 135 & $0.948(0.664-1.353)$ & 0.769 & $0.945(0.660-1.354)$ & 0.759 \\
\hline
\end{tabular}

$\dagger$ P-value was calculated by unconditional logistic regression analysis adjusted for age and sex.

Influence of rs13181 polymorphism combined with smoking on the risk of PC

With non-smoking individuals carrying the wild AA genotype as reference, the risk of PC did not increase in individuals carrying the AA genotype and with a smoking history $(p>0.05)$. The risk of PC increased by a factor of 0.384 in non-smokers carrying the mutant $\mathrm{C}$ allele and that were $(\mathrm{AC}+\mathrm{CC})(p=0.150)$, and in smokers carrying the mutant $\mathrm{C}$ allele and that were $(\mathrm{AC}+\mathrm{CC})$. Meanwhile, the risk of PC increased by 2.343 times $(p=0.002)$ in individuals who smoked $\geq 20$ cigarettes daily, 2.309 times $(p=0.015)$ in individuals who smoked $\geq 14$ packs per year, 3.013 times $(p=0.032)$ in the individuals who smoked $\geq 24$ packs per year, and 4.011 times $(p=0.010)$ in the individuals who smoked $\geq 37$ packs per year (Tables 7 and 8). 


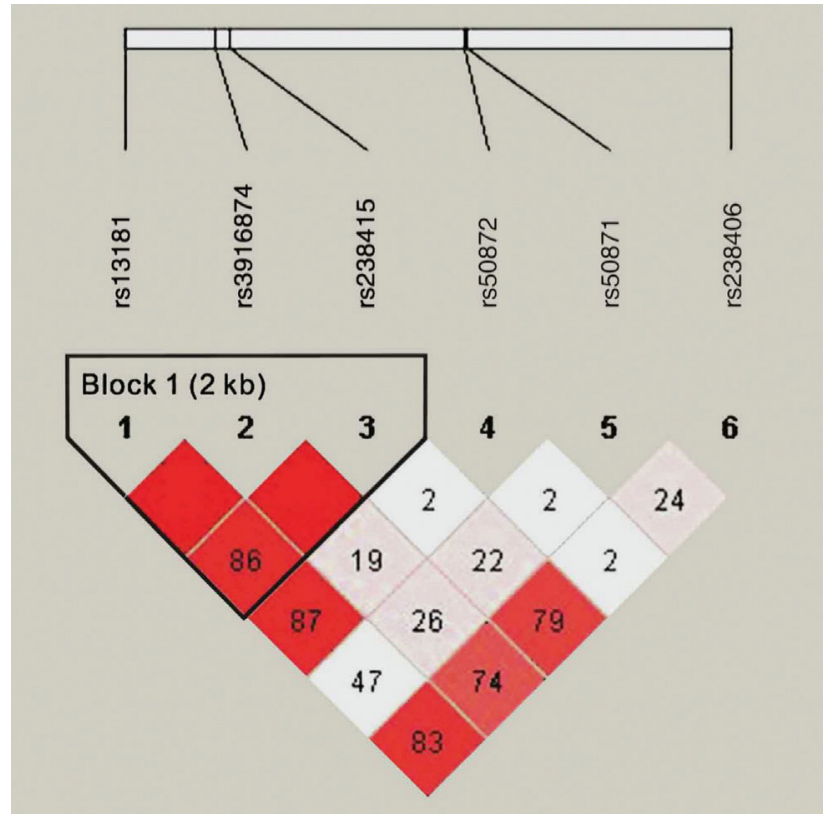

Figure 1 - Linkage disequilibrium (LD) plot of the SNPs in XPD. Six SNP sites of XPD gene are shown in the upper part of the figure; the number in the box in the lower part shown the $100 x \mathrm{D}$ 'value (D: linkage disequilibrium parameter). A standard color scheme is used to display LD with bright red for very strong $\operatorname{LD}\left(\operatorname{LOD} \geq 2, \mathrm{D}^{\prime}=1\right)$, white for no $\operatorname{LD}(\operatorname{LOD}<2$, $D^{\prime}<1$ ), pink red for intermediate LD.

Table 6 - XPD haplotype frequencies and associations with pancreatic cancer risk in the Chinese Han population.

\begin{tabular}{lcccc}
\hline Haplotype & Case $(\%)$ & Control $(\%)$ & OR $(95 \% \mathrm{CI})$ & $p$ \\
\hline AGG & 0.479 & 0.402 & $1.401(1.065 \sim 1.844)$ & 0.016 \\
AGC & 0.261 & 0.304 & $0.824(0.610 \sim 1.114)$ & 0.209 \\
ACC & 0.140 & 0.165 & $0.838(0.574 \sim 1.222)$ & 0.357 \\
CGC & 0.103 & 0.125 & $0.816(0.532 \sim 1.251)$ & 0.350 \\
\hline
\end{tabular}

Haplotype constructed with the order of SNPs: rs13181, rs3916874 and rs238415.

\section{Discussion}

Studies have shown that the risk of breast cancer, esophageal cancer, liver cancer, lymphoma, lung cancer and melanoma was increased in individuals carrying the XPD 751Gln variant allele (Kertat et al., 2008; Yan et al., 2014; Wu et al., 2014; Wang et al., 2015). However, the conclusions were not consistent. Studies conducted by Sun et al. (2015) revealed that the risk of melanoma was not increased in Caucasian populations carrying XPD 751Gln variant alleles. Furthermore, the polymorphisms of XPD Lys751Gln and Asp312Asn had no relationship with the susceptibility of non-Hodgkin's lymphoma (Chen et al., 2015), and meta-analysis results revealed that the polymorphism of XPD Lys751Gln was not associated with the risk of liver cancer (Zhang and Mou, 2013).

In the present study, we investigated the association of XPD codon 751 genotypes with PC susceptibility in the Chinese Han population. The results showed that the polymorphism at 5 tag-SNP loci was not related with the genetic susceptibility to $\mathrm{PC}$, but that the $\mathrm{AC}$ and $\mathrm{CC}$ genotypes of XPD codon 751 were associated with a higher risk of PC (Table 5). Allelic frequency analysis results also revealed that the $\mathrm{C}$ allele of XPD codon 751 was associated with a higher risk of PC (Table 4). Additionally, the haplotype AGG, which consists of rs13181, rs3916874 and rs238415, was associated with an increased risk of PC (Table 6). To the best of our knowledge, this is the first epidemiological study based on molecular genetics to determine a significant association between the XPD codon 751 genotype and the susceptibility to PC in an analysis including a genetic-lifestyle interaction. In 2007 it was first reported that the XPD codon 312 polymorphisms might be a genetic risk modifier for smoking-related PC (Jiao et al., 2007). Subsequently, the XPD codon 312 polymorphisms was also shown to be associated with PC risk (McWilliams et al., 2008). Since then, few reports have focused on investigating the associations of three common XPD polymorphisms (codon 156, codon 312 and codon 751) with PC risk among different ethnicities. Our positive findings for XPD codon

Table 7 - Correlation between daily cigarette amounts a with rs13181-locus polymorphic genotypes and susceptibility of pancreatic cancer.

\begin{tabular}{|c|c|c|c|c|c|}
\hline Genotype & Cigarettes a day & Patients group (cases) & Control group (cases) & OR $(95 \% \mathrm{CI}) \dagger$ & $p^{\dagger}$ \\
\hline \multirow[t]{4}{*}{ AA } & 0 (no smoking) & 64 & 99 & 1.000 & \\
\hline & $\leq 9$ & 6 & 11 & $0.855(0.305 \sim 2.413)$ & 0.738 \\
\hline & $10 \sim 19$ & 14 & 19 & $1.126(0.539 \sim 2.463)$ & 0.729 \\
\hline & $\geq 20$ & 34 & 38 & $1.371(0.783 \sim 2.418)$ & 0.266 \\
\hline \multirow[t]{4}{*}{$\mathrm{AC}+\mathrm{CC}$} & 0 (no smoking) & 62 & 68 & $1.384(0.896 \sim 2.259)$ & 0.150 \\
\hline & $\leq 9$ & 9 & 5 & $2.772(0.904 \sim 8.695)$ & 0.071 \\
\hline & $10 \sim 19$ & 13 & 12 & $1.656(0.732 \sim 3.923)$ & 0.237 \\
\hline & $\geq 20$ & 24 & 11 & $3.343(1.567 \sim 7.472)$ & 0.002 \\
\hline
\end{tabular}

$\dagger$ P-value was calculated by unconditional logistic regression analysis adjusted for age and sex. 
Table 8 - Relationship between total cigarettes per year with rs13181-locus polymorphic genotypes and susceptibility of pancreatic cancer.

\begin{tabular}{|c|c|c|c|c|c|}
\hline Genotype & Total cigarettes (packs per year) & Patients group (cases) & Control group (cases) & OR $(95 \% \mathrm{CI}) \dagger$ & $p_{\dagger}^{\dagger}$ \\
\hline \multirow[t]{5}{*}{ AA } & 0 (no smoking) & 64 & 99 & 1.000 & \\
\hline & $<14$ & 6 & 23 & $0.392(0.147 \sim 1.062)$ & 0.061 \\
\hline & $14 \sim 23.9$ & 21 & 20 & $1.620(0.809 \sim 3.178)$ & 0.171 \\
\hline & $24 \sim 36.9$ & 15 & 16 & $1.424(0.665 \sim 3.122)$ & 0.352 \\
\hline & $\geq 37$ & 12 & 9 & $2.071(0.867 \sim 5.181)$ & 0.124 \\
\hline \multirow[t]{5}{*}{$\mathrm{AC}+\mathrm{CC}$} & 0 (no smoking) & 62 & 68 & $1.431(0.987 \sim 2.256)$ & 0.152 \\
\hline & $<14$ & 10 & 14 & $1.116(0.506 \sim 2.729)$ & 0.857 \\
\hline & $14 \sim 23.9$ & 15 & 7 & $3.309(1.286 \sim 8.547)$ & 0.015 \\
\hline & $24 \sim 36.9$ & 13 & 4 & $5.011(1.549 \sim 16.181)$ & 0.010 \\
\hline & $\geq 37$ & 8 & 3 & 4.013(1.007 15.974) & 0.032 \\
\hline
\end{tabular}

$\uparrow$ P-value was calculated by unconditional logistic regression analysis adjusted for age and sex.

751 are inconsistent with previous investigations that reported that the $\mathrm{C}$ allele of XPD codon 751 is not a genetic risk factor.

The results of this study revealed that the risk of PC was increased in individuals carrying the mutant allele $\mathrm{C}$ (AC, CC, and $\mathrm{AC}+\mathrm{CC}$ ) at XPD Lys751Gln compared with the wild genotype AA. Taking non-smoking individuals who carry the wild genotype AA as reference, the risk of $\mathrm{PC}$ was significantly increased in smokers who carry allele $\mathrm{C}(\mathrm{AC}+\mathrm{CC})$ mutations and whose smoking amounts were $\geq$ 20 cigarettes daily and $\geq 14$ packs per year. This indicates that smoking can increase the risk of $\mathrm{PC}$, and that this risk is increased with the increase in daily cigarette smoking and packs per year. Furthermore, smokers who carry the XPD $751 \mathrm{Gln}$ variant allele are more likely to suffer from PC.

There was an interaction between the XPD Lys $751 \mathrm{Gln}$ polymorphism and smoking, which was consistent with the results of the meta-analysis in lung cancer performed by Feng et al. (2012). The reasoning in that analysis was as follows: (1) PC is a polygenic disease with a genetic predisposition, and approximately $10 \%$ of the patients with PC have a genetic background (Pancreatic surgery group of Chinese Surgical Society, 2014); (2) smoking is a recognized risk factor for PC (Tranah et al., 2011; Ryan et al., 2014), and tobacco contains a variety of toxic and harmful substances that can produce free radicals, which can lead to DNA damage and cell carcinogenesis (Halliwell and Whiteman, 2004; Ozguner et al., 2005; Li et al., 2011); (3) studies performed by Wlodarczyk and Nowicka (2012) revealed that the DNA repair ability of individuals who carry the wild homozygote Lys/Lys combination was higher than that of individuals who are heterozygous Lys/Gln or mutant homozygous Gln/Gln. The results of this study revealed that the risk of PC was increased in individuals who carry the XPD 751Gln allele, suggesting that a codon 751 mutation may lead to a decline in DNA repair capacity and increase tumor susceptibility; (4) the XPD 751 site is located in the carboxyl terminus, and its conservation is poor. The conversion of A to C (Lys to Gln) in codon 751 may affect the interaction between its protein product and p44 (a subunit of the multi-enzyme complex TF II H), reduce helicase activity, and thereby result in defects in nucleotide excision repair. This can induce the decline in transcription activity and an abnormal response to cell apoptosis, which may increase cancer susceptibility (Egly and Coin, 2011; Wlodarczyk and Nowicka, 2012); (5) the polymorphism changes at other sites in the introns were not functional polymorphisms. They only played a role in splicing, in translation bypass, or in post-translational processing. Hence, they are unlikely to affect the protein function and might not be related to the risk of PC.

In summary, in individuals who carry the mutant gene, the risk of $\mathrm{PC}$ might be reduced through actions like quitting smoking, smoking control in public places, and early intervention in high-risk populations. The major limitations of our study were the relatively small sample size and the inclusion of Chinese Han participants only, which limits generalizability across other populations. In the future, the combined detection of more samples, and multiple gene loci will be required. Research on the interaction between genes and environment are also needed for establishing an effective mode of screening, treatment and prevention for PC.

\section{Acknowledgments}

This study was supported by research grants from the National Natural Science Funding of China (No. 30960433). We thank all the participants and all the colleagues at the Tissue Bank for their efforts in the collection of samples and questionnaires.

\section{References}

Benhamou S and Sarasin A (2002) ERCC2/XPD gene polymorphisms and cancer risk. Mutagenesis 17:463-469. 
Benhamou S and Sarasin A (2005) ERCC2/XPD gene polymorphisms and lung cancer: A HuGE review. Am J Epidemiol 161:1-14.

Bosetti C, Lucenteforte E, Silverman DT, Petersen G, Bracci PM, Ji BT, Negri E, Li D, Risch HA, Olson SH, et al. (2012) Cigarette smoking and pancreatic cancer: An analysis from the international pancreatic cancer case-control consortium (Panc4). Ann Oncol 23:1880-1888.

Chen S, Zhu JH, Wang F, Huang SY, Xue WQ, Cui Z, He J and Jia WH (2015) Association of the Asp312Asn and Lys751Gln polymorphisms in the XPD gene with the risk of nonHodgkin's lymphoma: evidence from a meta-analysis. Chin J Cancer 34:108-114.

Egly JM and Coin F(2011) A history of TFIIH: Two decades of molecular biology on a pivotal transcription/repair factor. DNA Repair 10:714-721.

Feng Z, Ni Y, Dong W, Shen H and Du J (2012) Association of ERCC2/XPD polymorphisms and interaction with tobacco smoking in lung cancer susceptibility: A systemic review and meta-analysis. Mol Biol Rep 39:57-69.

Halliwell B and Whiteman M (2004) Measuring reactive species and oxidative damage in vivo and in cell culture: How should you do it and what do the results mean? Br J Pharmacol 142:231-255.

Iodice S, Gandini S, Maisonneuve P and Lowenfels AB (2008) Tobacco and the risk of pancreatic cancer: a review and meta-analysis. Langenbecks Arch Surg 393:535-545.

Jacobs EJ, Chanock SJ, Fuchs CS, Lacroix A, McWilliams RR and Steplowski E (2010) Family history of cancer and risk of pancreatic cancer: A pooled analysis from the Pancreatic Cancer Cohort Consortium (PanScan). Int $\mathrm{J}$ Cancer 127:1421-1428.

Jiao L, Hassan MM, Bondy ML, Abbruzzese JL, Evans DB and Li D (2007) The XPD Asp312Asn and Lys751Gln polymorphisms, corresponding haplotype, and pancreatic cancer risk. Cancer Lett 245:61-68.

Kertat K, Rosdahl I, Sun XF, Synnerstad I and Zhang H (2008) The Gln/Gln genotype of XPD codon 751 as a genetic marker for melanoma risk and Lys/Gln as an important predictor for melanoma progression: a case control study in the Swedish population. Oncol Rep 20:179-183.

Larsson SC, Orsini N and Wolk A (2007) Body mass index and pancreatic cancer risk: a meta-analysis of prospective studies. Int J Cancer 120:1993-1998.

Li Z, Guan W, Li MX, Zhong ZY, Qian CY, Yang XQ, Liao L, Li ZP and Wang D (2011) Genetic polymorphism of DNA base-excision repair genes (APE1, OGG1 and XRCC1) and their correlation with risk of lung cancer in a Chinese population. Arch Med Res 42:226-234.

Lunn RM, Helzlsouer KJ, Parshad R, Umbach DM, Harris EL, Sanford KK and Bell DA (2000) XPD polymorphisms: Effects on DNA repair proficiency. Carcinogenesis 21:551555.

Maisonneuve P and Lowenfels AB (2010) Epidemiology of pancreatic cancer: An update. Dig Dis 28:645-656.

McWilliams RR, Bamlet WR, Cunningham JM, Goode EL, de Andrade M, Boardman LA and Petersen GM (2008) Polymorphisms in DNA repair genes, smoking, and pancreatic adenocarcinoma risk. Cancer Res 68:4928-4935.
Ozguner F, Koyu A and Cesur G (2005) Active smoking causes oxidative stress and decreases blood melatonin levels. Toxicol Ind Health 21:21-26.

Pancreatic Surgery group of Chinese Surgical Society (2014) Guidelines for the diagnosis and treatment of pancreatic cancer (2014). Zhonghua Wai Ke Za Zhi 52:881-887.

Qian F, Ogundiran T, Hou N, Ndom P, Gakwaya A, Jombwe J, Morhason-Bello I, Adebamowo C, Ademola A, Ojengbede O, et al. (2014) Alcohol consumption and breast cancer risk among women in three sub-Saharan African countries. PLoS One 9:e106908.

Ryan DP, Hong TS and Bardeesy N (2014) Pancreatic adenocarcinoma. N Engl J Med 371:2140-2141.

Shen MR, Jones IM and Mohrenweiser H (1998) Nonconservative amino acid substitution variants exist at polymorphic frequency in DNA repair genes in healthy humans. Cancer Res 58:604-608.

Siegel R, Naishadham D and Jemal A (2013) Cancer statistics, 2013. CA Cancer J Clin 63:11-30.

Sun Y, Zhang H, Ying H, Jiang W and Chen Q (2015) A metaanalysis of XPD/ERCC2 Lys751Gln polymorphism and melanoma susceptibility. Int J Clin Exp Med 8:1387413878.

Talamini R, Polesel J, Gallus S, Dal Maso L, Zucchetto A, Negri E, Bosetti C, Lucenteforte E, Boz G, Franceschi S, et al. (2010) Tobacco smoking, alcohol consumption and pancreatic cancer risk: a case-control study in Italy. Eur J Cancer 46:370-376.

Taylor EM, Broughton BC, Botta E, Stefanini M, Sarasin A, Jaspers NG, Fawcett H, Harcourt SA, Arlett CF and Lehmann AR (1997) Xeroderma pigmentosum and trichothiodystrophy are associated with different mutations in the XPD (ERCC2) repair/transcription gene. Proc Natl Acad Sci U S A 94:8658-8663.

Tranah GJ, Holly EA, Wang F and Bracci PM (2011) Cigarette, cigar and pipe smoking, passive smoke exposure, and risk of pancreatic cancer: A population-based study in the San Francisco Bay Area. BMC Cancer 11:138.

Wang Y, Zhao Y, Zhang A, Ma J, Wang Z and Zhang X. (2015) A meta-analysis of xeroderma pigmentosum gene D Lys751Gln polymorphism and susceptibility to hepatocellular carcinoma. Int J Clin Exp Pathol 8:12949-12954.

Wlodarczyk M and Nowicka G (2012) XPD gene rs13181 polymorphism and DNA damage in human lymphocytes. Biochem Genet 50:860-870.

Wu HY and Ding LY (2014) Comprehensive assessment of the association between XPD rs13181 polymorphism and lung cancer risk. Tumour Biol 35:8125-8132.

Wu KG, He XF, Li YH, Xie WB and Huang X (2014) Association between the XPD/ERCC2 Lys751Gln polymorphism and risk of cancer: evidence from 224 case-control studies. Tumour Biol 35:11243-11259.

Xiong T, Yang J, Wang H, Wu F, Liu Y, Xu R, Lv Z, Xue P, Cao $\mathrm{W}$ and Zhang Y (2014) The association between the Lys $751 \mathrm{Gln}$ polymorphism in the XPD gene and the risk of bladder cancer. Mol Biol Rep 41:2629-2634.

Yan Y, Liang H, Light M, Li T, Deng Y, Li M, Li S and Qin X (2014) XPD Asp312Asn and Lys751Gln polymorphisms and breast cancer susceptibility: a meta-analysis. Tumour Biol 35:1907-1915. 
Yuan H, Niu YM, Wang RX, Li HZ and Chen N (2011) Association between XPD Lys751Gln polymorphism and risk of head and neck cancer: a meta-analysis. Genet Mol Res 10:3356-3364.

Zhang RC and Mou SH (2013) Polymorphisms of excision repair gene XPD Lys751Gln and hOGG1 Ser326Cys might not be associated with hepatocellular carcinoma risk: a metaanalysis. Tumour Biol 34:901-907.

Associate Editor: Mara H. Hutz

License information: This is an open-access article distributed under the terms of the Creative Commons Attribution License (type CC-BY), which permits unrestricted use, distribution and reproduction in any medium, provided the original article is properly cited. 